\title{
La protección internacional de la objeción de conciencia: análisis comparado entre sistemas de derechos humanos y perspectivas en el sistema interamericano
}

Fecha de recepción: 22 de febrero de 2015

Fecha de aceptación: 5 de octubre de 2015

Doi: dx.doi.org/10.12804/acdi9.1.2016.07

\section{María Carmelina Londoño Lázaro* \\ Juana Inés Acosta López ${ }^{*}$}

Resumen: En este artículo se analiza el reconocimiento de la objeción de conciencia en tres sistemas internacionales de protección a los derechos humanos: el Sistema Interamericano, el Sistema Europeo y el Sistema de las Naciones Unidas. La perspectiva comparada que se adopta permite advertir los desarrollos comunes, las falencias y algunas tensiones a las que se han enfrentado los órganos internacionales en la decisión de casos controversiales. De este análisis se extraen algunas lecciones que pueden servir para la tutela de este derecho en el Sistema Interamericano.

* Doctora en Derecho, LLM, abogada. Directora de la Maestría en Derecho Internacional de la Universidad de La Sabana; miembro fundador de la Academia Colombiana de Derecho Internacional y de la Sociedad Latinoamericana de Derecho Internacional. Correo electrónico: maria.londono1@unisabana.edu.co

** Magíster en Derechos Humanos y Democratización y LLM en International Legal Studies. Directora del Programa de Derecho de la Universidad de La Sabana; presidente de la Academia Colombiana de Derecho Internacional; agente representante de Colombia ante la Corte Interamericana de Derechos Humanos. Correo electrónico: juanacl@unisabana. edu.co

Para citar este artículo: Londoño, María Carmelina \& Acosta, Juana Inés, "La protección internacional de la objeción de conciencia: análisis comparado entre sistemas de derechos humanos y perspectivas en el Sistema Interamericano", Anuario Colombiano de Derecho Internacional (ACDI), 2016, 9, pp. 233-272. Doi: dx.doi. org/10.12804/acdi9.1.2016.07 
Palabras clave: Objeción de conciencia, Derecho a la libertad de conciencia y religión, Sistemas internacionales de protección de derechos humanos, Sistema Interamericano de Derechos Humanos.

International Protection of Conscientious Objection:
A Comparative Analysis of Human Rights Systems
and Perspectives of the Inter- American System

Abstract: In this article, the recognition of conscientious objection in three international systems for the protection of human rights is analyzed: the Inter-American system, the European system and the United Nations system. The comparative system which is adopted allows for notifications as to common developments, the failings and some tensions which have been confronted by international organs in controversial cases. From this analysis are drawn some lessons which may serve for the guardianship of this law in the Inter- American system.

Keywords: conscientious objection, right to freedom of conscience and religion, international systems for the protection of human rights, the Inter-American system of Human Rights.

A proteção internacional da objeção de consciência: análise comparado entre sistemas de direitos humanos e perspectivas no Sistema Interamericano

Resumo: Neste artigo analisa-se o reconhecimento da objeção de consciência em três sistemas internacionais de proteção aos direitos humanos: o Sistema Interamericano, o Sistema Europeu e o Sistema das Nações Unidas. A perspectiva comparada que se adota permite advertir os desenvolvimentos comuns, as falências e algumas tensões às que se têm enfrentado os órgãos internacionais na decisão de casos controversos. Desta análise extraem-se algumas lições que podem server para a tutela deste direito no Sistema Interamericano.

Palavras-chave: Objeção de consciência, Direito à liberdade de consciência e religião, Sistemas internacionais de proteção de direitos humanos, Sistema Interamericano de Direitos Humanos. 


\section{Introducción}

La objeción de conciencia es hoy en día reconocida en los principales pactos y declaraciones de derechos humanos como un derecho contenido dentro de la libertad de pensamiento, conciencia y religión. ${ }^{1}$ Sin embargo, sabiendo que estos textos no hicieron referencia expresa a la objeción de conciencia, se ha cuestionado su autonomía como derecho y el alcance de su protección. El objeto de este artículo es exponer el recorrido trazado por la jurisprudencia y doctrina internacional en esta materia, con el ánimo de advertir, en especial dentro del contexto del Sistema Interamericano, sobre la necesidad de descubrir la importancia de esta figura, su reconocimiento como un derecho independiente y su directa relación con la garantía de aquellas libertades.

De conformidad con lo anterior, el presente estudio responde a dos objetivos centrales. En primer lugar, analizar sistemática y críticamente el alcance de la protección a la objeción de conciencia en los principales sistemas de derechos humanos y su reconocimiento como derecho humano. Para estos efectos, se ha dividido el artículo en tres apartados centrales, referido cada uno a un sistema: el Sistema Interamericano de Derechos Humanos (SIDH), el Sistema Europeo de Derechos Humanos (SEDH) y el Sistema Universal (SUDH). ${ }^{2}$ El orden definido no es aleatorio. Se ha querido iniciar por el SIDH para poner en evidencia sus más escasos desarrollos, también porque iniciar con este sistema facilita mantener el

1 Declaración Universal de los Derechos Humanos, artículo 18: “Toda persona tiene derecho a la libertad de pensamiento, de conciencia y de religión; este derecho incluye la libertad de cambiar de religión o de creencia, así como la libertad de manifestar su religión o su creencia, individual y colectivamente, tanto en público como en privado, por la enseñanza, la práctica, el culto y la observancia". Con términos muy semejantes, esta disposición básica se reproduce en el Pacto Internacional de Derechos Civiles y Políticos, artículo 18; el Convenio Europeo para la Protección de los Derechos Humanos y las Libertades Fundamentales, artículo 9 ${ }^{\circ}$; y la Convención Americana sobre Derechos Humanos, artículo 12. La Carta Africana de Derechos Humanos y de los Pueblos también reconoce genéricamente la libertad de conciencia y religión en el artículo $8^{\circ}$.

2 No se hace referencia expresa al sistema africano, por cuanto no se evidencian casos sobre esta materia. De manera excepcional, una breve referencia a la objeción de conciencia en relación con la práctica del aborto puede verse en la Observación General 2 de la Comisión Africana de Derechos Humanos, sobre los artículos 14(1)(a), (b), (c), (f) y 14(2) (a) y (c) del Protocolo a la Carta Africana sobre Derechos Humanos y de los Pueblos en relación con los derechos de las mujeres en África, observación adoptada en la sesión ordinaria 55, que tuvo lugar entre el 28 de abril y el 12 de mayo de 2014, en Angola. 
enfoque propuesto y, probablemente, esta estructura puede servir al lector para adelantar un análisis comparativo a lo largo del documento desde la óptica del SIDH.

El segundo objetivo se centra en advertir los vacíos existentes y las oportunidades que tendrían los órganos del SIDH en relación con el reconocimiento y regulación de la objeción de conciencia. En efecto, la tesis que se sustentará es que en escenarios pluralistas el reconocimiento del derecho a la objeción de conciencia es una garantía para la convivencia pacífica, con una clara función 'conciliadora', puesto que facilita la vigencia armónica de los derechos humanos, enfrentados aparentemente en casos difíciles. Esas reflexiones se plantean en la cuarta y última parte del documento, que obra a modo de colofón de todo lo expuesto.

\section{La objeción de conciencia en el Sistema Interamericano de Derechos Humanos}

\subsection{La objeción de conciencia en la Convención Americana sobre Derechos Humanos}

La Convención Americana sobre Derechos Humanos (CADH) hace referencia expresa a la objeción de conciencia en uno solo de sus artículos. En efecto, el artículo $6^{\circ}$, relativo a la prohibición de esclavitud y servidumbre, establece en su numeral 3.b que "no constituyen trabajo forzoso u obligatorio [...] el servicio militar y, en los países donde se admite exención por razones de conciencia, el servicio nacional que la ley establezca en lugar de aquél" (cursivas fuera del texto original).

De forma semejante a lo que ocurre con otros tratados internacionales de derechos humanos que preceden a la $\mathrm{CADH}$, si bien se reconoce de modo manifiesto la libertad de conciencia, no hay expresa referencia a la objeción de conciencia como derecho protegido. Es así como en el ámbito interamericano el artículo $12 \mathrm{CADH}$ relativo a la libertad de conciencia y de religión establece que "toda persona tiene derecho a la libertad de conciencia y de religión. Este derecho implica la libertad de conservar su religión o sus creencias, o de cambiar de religión o de creencias, así como la libertad de profesar y divulgar su religión o sus creencias, individual o colectivamente, [...]" (cursivas fuera del texto original), y este derecho solo podrá ser limitado por causas "prescritas por ley y que sean necesarias para proteger la seguridad, el orden, la salud o la moral públicas o los derechos o libertades de los demás [...]". 
Por último, el artículo 11 protege la honra y la dignidad, y en particular establece que "2) Nadie puede ser objeto de injerencias arbitrarias o abusivas en su vida privada, en la de su familia, en su domicilio o en su correspondencia, ni de ataques ilegales a su honra o reputación. 3) Toda persona tiene derecho a la protección de la ley contra esas injerencias o esos ataques" (cursivas fuera del texto original).

En el entendido de que la objeción de conciencia preserva el derecho a no ser obligado a actuar — conforme a un deber jurídico- contra las convicciones más arraigadas del fuero interior o la propia conciencia, se trata de un corolario de la libertad de conciencia, por lo que las disposiciones convencionales referidas son suficientes para reconocer y desarrollar tal derecho. Sin embargo, hasta ahora los casos del SiDH en esta materia son muy escasos.

\subsection{Casos relacionados con la objeción de conciencia al servicio militar obligatorio}

En el caso Sabli Vera vs. Chile $e^{3}$ (2005), la Comisión Interamericana de Derechos Humanos (CIDH) analizó la situación de tres jóvenes, quienes presentaron solicitudes individuales ante la oficina de partes del Departamento de Reclutamiento de la Dirección General de Movilización del Estado de Chile, en las cuales expresaban su objeción de conciencia al servicio militar obligatorio y a su participación en dicho servicio militar por ser una incursión arbitraria en su vida privada y una injerencia arbitraria con sus planes de vida. Las presuntas víctimas nunca recibieron respuesta a las solicitudes presentadas y, pese a la expresa objeción de conciencia, sus nombres fueron incluidos en el llamamiento ordinario y obligatorio a rendir el servicio militar. Los jóvenes no se presentaron pero nunca fueron citados o enjuiciados por no haberse presentado. Los peticionarios alegaban que el Estado era responsable por la violación del derecho a la objeción de conciencia, afectando directamente su libertad de conciencia y religión y su vida privada, en conexión con la obligación de respetar y garantizar los derechos establecidos en la Convención. ${ }^{4}$

La CIDH analizó este caso a la luz de los artículos $6^{\circ}$ y 12 de la Convención e indicó que, de la lectura conjunta de estos dos artículos, podía deducirse que se reconoce expresamente el derecho a la condición de objetor de conciencia en el servicio militar obligatorio en los países

3 CIDH, Caso 12.219, Sabli Vera vs. Chile, Informe No 43/05, 10 de marzo de 2005.

4 Supra nota 3. 
en que esta condición está reconocida en la legislación interna. ${ }^{5}$ Sin embargo, la cuestión es menos clara en aquellos países en los que no existe ley pertinente o la ley nacional no reconoce la objeción de conciencia. En Chile, la condición de objetor de conciencia no estaba reconocida en las leyes nacionales, por lo cual el Estado argumentó que no estaba obligado a otorgarla, dado que el artículo 12 de la Convención le autorizaba expresamente a limitar el ámbito del derecho por razones de seguridad nacional. ${ }^{6}$

$\mathrm{Al}$ respecto, la CIDH afirmó en su informe:

Un breve relevamiento de la jurisprudencia sobre esta cuestión en el sistema europeo y del Comité de Derechos Humanos de la ONU revela que los órganos internacionales de derechos humanos se muestran renuentes a crear el derecho a la condición de objetor de conciencia en el contexto del derecho a la libertad de conciencia en los países en que aquella condición no ha sido reconocida por su legislación nacional. Sin embargo, esos mismos órganos sí reconocen el derecho, en el marco de la libertad de conciencia, en los países en que su legislación reconoce la condición de objetor de conciencia, pero entonces surgen controversias en cuanto a si es suficiente que el objetor de conciencia así se autodefina, o si el Comité dejará que el Estado aplique una prueba administrada internamente que exija una demostración de adhesión a un sistema de creencias pacifista o religioso para respaldar la conclusión de que se ha configurado dicha condición.

La Comisión opina que el hecho de que el Estado chileno no reconozca la condición de 'objetor de conciencia' en su legislación interna y no reconozca a [los peticionarios] como 'objetores de conciencia' del servicio militar obligatorio no constituye una interferencia con su derecho a la libertad de conciencia. La Comisión entiende que la Convención Americana no prohíbe el servicio militar obligatorio y que su artículo 6(3)(b) prevé específicamente el servicio militar en los países en que no se reconoce a los objetores de conciencia. ${ }^{7}$

En este sentido, la CIDH concluyó que Chile no era responsable ni de la violación del derecho a la libertad de conciencia (artículo 12), ni de la violación al derecho a la honra y la dignidad (artículo 11) CADH. Como

5 Supra nota 3, párr. 86.

6 Ibíd.

$7 \quad$ Supra nota 3, párrs. 87 y 88. 
puede colegirse de la decisión, parecería que en esta materia el SIDH se inclina por aceptar un cierto tipo de margen nacional de apreciación a favor de los Estados, en relación con la posibilidad de reconocer y regular la objeción de conciencia en el servicio militar. Sobre esta apreciación se ahondará más adelante para consolidar un argumento que tendrá especial peso en las conclusiones.

En el caso de Alfredo Díaz Bustos vs. Bolivia (2005), el peticionario alegaba que por ser testigo de Jehová se le vulneró su derecho a la objeción de conciencia, dado que la Ley del Servicio Nacional de Defensa boliviano establecía la desigualdad entre católicos y fieles de otras confesiones religiosas, siendo que, para los primeros, la exención del servicio militar era posible, no siendo así para los demás. Así mismo, el peticionario alegó que el Estado boliviano había violado el derecho a la protección judicial, ya que, mediante sentencia definitiva del Tribunal Constitucional, se estableció que los asuntos sobre el derecho a la objeción de conciencia con relación al servicio militar obligatorio no podían ser puestos en conocimiento de la justicia. ${ }^{9}$ Así las cosas, se alegó que los hechos generaban una violación a los derechos a la igualdad (artículo 24), la protección judicial (artículo 25) y la libertad de conciencia y de religión (artículo 12) CADH.

Este caso tuvo una terminación anticipada por solución amistosa. En ella, el Estado se comprometió, entre otros, a: i) entregar a la víctima la libreta militar gratuita; ii) emitir una resolución ministerial que aseguraba que la víctima, por su condición de objetor de conciencia, no sería destinada al frente de batalla; y iii) promover legislación sobre la objeción de conciencia para el servicio militar. ${ }^{10}$

En el caso Xavier Alejandro León Vega vs. Ecuador ${ }^{11}$ (2006), la Comisión analizó la situación de un miembro activo del movimiento de objetores de conciencia de Ecuador. La presunta víctima alegó que no se le había otorgado la cédula de objetor de conciencia o una equivalente, que tuviera los mismos efectos jurídicos que la cédula militar de las personas que habían realizado el servicio militar obligatorio, a pesar de que es un derecho reconocido por la legislación ecuatoriana. Manifestó que esto afectaba

\footnotetext{
8 CIDH, caso Alfredo Diaz Bustos vs. Bolivia, Informe No 97/05, Petición 14/04, solución amistosa, 27 de octubre de 2005.

9 Supra nota 8.

10 Supra nota 8.

11 CIDH, Xavier Alejandro León Vega vs. Ecuador, Informe No 22/06, Petición 278-02, admisibilidad, 2 de marzo de 2006.
} 
aspectos de su vida incluyendo su posibilidad de trabajar y crear una empresa, su libertad para entrar y salir del país y continuar con su educación. En concreto, alegó la violación del derecho a la libertad de conciencia y religión, a la libertad de circulación y movimiento, al derecho a la educación, a la falta de adecuación de la legislación interna a los compromisos internacionales y a la obligación de respetar y garantizar el libre y pleno ejercicio de los derechos de las personas.

La Comisión reiteró que el derecho a la objeción de conciencia frente al servicio militar obligatorio se puede derivar de los derechos a la honra y la dignidad (artículo 11) y el derecho a la libertad de conciencia y de religión (artículo 12), en conjunto con el 6.3.b, cuando la objeción de conciencia esté reconocida expresamente en la legislación del Estado en consideración. En este caso, la CIDH entendió que, efectivamente, a la luz del derecho nacional y las provisiones convencionales mencionadas, el Estado de Ecuador había violado los derechos alegados por la víctima, de conformidad con los artículos 1.1, 2, 11, 12.1 y 22.2 de la CADH y el artículo 13.1 del Protocolo de San Salvador.

Finalmente, resulta interesante mencionar el caso Luis Gabriel Caldas vs. Colombia ${ }^{12}$ (2010). La petición hacía referencia a la presunta violación del derecho a la honra y la dignidad, las garantías judiciales y la protección judicial (artículos 11, $8^{\circ}$ y $25 \mathrm{CADH}$ ), en razón a que la presunta víctima fue llamada a prestar servicio militar obligatorio luego de culminar sus estudios, a pesar de que, mediante comunicaciones escritas y verbales, manifestó que, conforme a su convicción moral, era una persona pacífica y, por ello, se negaba a prestar dicho servicio. Pese a que el interesado solicitó en dos oportunidades prestar un servicio social alternativo, sus peticiones fueron rechazadas. Por lo tanto, ante la insistencia de su negativa a cumplir el servicio militar, se inició una investigación en la justicia penal militar de Colombia, proceso que culminó en una condena de 7 meses de arresto. Aunque se trató de un expediente archivado en 2010 por la CIDH a falta de mayor información del peticionario, conviene tenerlo en cuenta por el paralelo que presenta con el caso Bayatyan (2011), en el que el Tribunal Europeo de Derechos Humanos (TEDH) da un giro jurisprudencial notorio y reconoce la objeción de conciencia como un derecho autónomo, como se explicará más adelante. ${ }^{13}$

12 CIDH, caso Luis Gabriel Caldas León vs. Colombia, No 137/10, Informe No 137/10, Caso 11.596, 23 de octubre de 2010.

13 Infra 2.1.3. Bayatyan vs. Armenia (Gran Sala), Aplicación No 23459/03, decisión del 7 
La analogía de los dos casos y su distinto desarrollo en cada sistema permiten advertir una realidad más amplia: el reconocimiento de la objeción de conciencia en el SIDH es todavía muy incipiente en comparación con el alcance que ha ido ganando en el TEDH. La posición adoptada en la Corte IDH en un caso reciente que se analizará enseguida refuerza la misma tesis.

\subsection{Otros casos de objeción de conciencia: tratamientos médicos}

La Corte Interamericana de Derechos Humanos (Corte IDH) no ha tenido que resolver casos en los que el problema jurídico central esté directamente relacionado con la objeción de conciencia, sin embargo, podría decirse que ha desaprovechado oportunidades para definir derroteros de su jurisprudencia en la materia. Teniendo en cuenta el alcance de la objeción de conciencia y el consenso más o menos generalizado sobre las típicas situaciones en las que se invoca este derecho, ${ }^{14}$ puede afirmarse que el caso Artavia Murillo y otros vs. Costa Rica ${ }^{15}$ referido a la fecundación in vitro (FIV) es un caso paradójico porque la Corte IDH va más allá de lo solicitado por los peticionarios en relación con el derecho a la vida y, sin embargo, no se toma la misma libertad respecto de la objeción de conciencia. ${ }^{16}$

de julio de 2011. Sobre la evolución de la jurisprudencia del Tribunal Europeo de Derechos Humanos en esta materia, pueden verse los siguientes estudios: Martínez-Torrón, Javier, "El derecho internacional y las objeciones de conciencia", en Objeción de conciencia, Colección Cuadernos del Instituto de Investigaciones Jurídicas, UNAM, 1998, pp. 111-136; Sierra Madero, Dora María, La objeción de conciencia en México. Bases para un adecuado marco jurídico, UnAm, México, 2012; Navarro-Vals, Rafael \& Martínez-Torrón, Javier, Confictos entre conciencia y ley: las objeciones de conciencia, Iustel, Madrid, 2012; Cañamares Arribas, Santiago, "La evolución de la doctrina del Tribunal Europeo de Derechos Humanos en materia de objeción de conciencia", Revista de Derecho Público, 2014, 23, (46), pp. 37-58.

14 Sobre los tipos más frecuentes de objeción de conciencia puede verse el estudio extenso y sistemático de Llamazares Fernández, Dionisio \& Llamares Calzadilla, María Cruz, Derecho de la libertad de conciencia, Aranzadi Civitas, Navarra, 2007, pp. 341-490. En el mismo sentido, ver Navarro-Vals y Martínez-Torrón, Conflictos entre conciencia y ley..., op. cit. En un estudio más breve pero suficientemente claro, se pueden verificar también los típicos ámbitos de aplicación de la objeción de conciencia: López Guzmán, José, ¿Qué es la objeción de conciencia?, Serie Persona y Cultura, Eunsa, Pamplona, 2011.

15 Corte IDH, caso Artavia Murillo y otros (fecundación in vitro) vs. Costa Rica, excepciones preliminares, fondo, reparaciones y costas, sentencia del 28 noviembre de 2012, Serie C No 257, párr. 185 .

16 La Corte IDH en numerosos casos, sobre la base del principio iura novit curia, ha extendido el alcance de sus argumentos a otros derechos no alegados por las partes, por lo que este 
La referencia a la objeción de conciencia hubiera tenido cabida toda vez que la misma Corte IDH admitió que en relación con las técnicas de fecundación artificial hay un amplio debate y no existe un consenso científico, ético, religioso ni moral relativo a la pregunta fundamental sobre el comienzo de la vida humana. ${ }^{17}$

Poner de presente el hecho de que no existe un consenso unánime y que el contenido mismo de la materia tiene, además de la dimensión jurídica, una dimensión ética, moral, filosófica y/o religiosa confirma la pertinencia que hubiera tenido la referencia a la objeción de conciencia, pues en última instancia esta figura jurídica es una concreción práctica de una libertad fundamental (religión y conciencia de acuerdo con el artículo $12 \mathrm{CADH}$ ) que permite reconciliar en casos concretos la contradicción grave que se presenta en el fuero individual entre una obligación de ley y una obligación de conciencia basada en las convicciones éticas, filosóficas, morales o religiosas de una persona. ${ }^{18}$

De hecho, resulta inconsecuente que, después de que la Corte IDH afirma:

Es claro que hay concepciones que ven en los óvulos fecundados una vida humana plena. Algunos de estos planteamientos pueden ser asociados a concepciones que le confieren ciertos atributos metafísicos a los embriones. Estas concepciones no pueden justificar que se otorgue prevalencia a cierto tipo de literatura científica al momento de interpretar el alcance del derecho a la vida consagrado en la Convención Americana, pues ello implicaría imponer un tipo de creencias especificas a otras personas que no las comparten ${ }^{19}$ (cursivas fuera del texto original),

el mismo tribunal pretenda imponer su propia perspectiva, ordenando como una medida general y obligatoria, que el Estado no solo autorice la

caso no hubiera sido excepcional en tal sentido. Así lo reconoció el tribunal recientemente en el caso Hermanos Landaeta Mejías y otros vs. Venezuela, providencia en la que enlista amplia jurisprudencia en la que la Corte IDH se pronuncia e interpreta disposiciones convencionales no alegadas por las partes, bajo el supuesto de que resultan relevantes para el análisis de los hechos en controversia. Ver Corte IDH, caso Hermanos Landaeta Mejias y otros vs. Venezuela, excepciones preliminares, fondo, reparaciones y costas, sentencia del $27 \mathrm{de}$ agosto de 2014, Serie C No 281, párr. 128.

17 Ibíd.

18 Navarro-Vals y Martínez-Torrón, Conflictos entre conciencia y ley..., op. cit., pp. 38-39.

19 Caso Artavia Murillo, op. cit., párr. 185. (Cursivas fuera del texto original). 
práctica de la FIV, sino que además la Caja Costarricense de Seguro Social incluya la FIV dentro de sus programas y tratamientos de infertilidad. ${ }^{20}$ Una resolución tan tajante y sobre la que se han hecho tantas críticas ${ }^{21}$ habría aminorado su impacto negativo si se hubiera hecho alusión a la objeción de conciencia, como defensa para el amplio sector (en particular, el personal sanitario) que se encuentra en desacuerdo con este tipo de técnicas.

En la misma sentencia, la Corte IDH también hubiera podido salvaguardar el derecho a la objeción de conciencia cuando se refiere, en general, a la prestación de servicios de salud sexual y reproductiva, ${ }^{22}$ sabiendo que en este campo no pocas veces se presentan dilemas éticos para el personal médico que asiste al paciente.

De hecho, en este ámbito, un par de años antes, la CIDH había proferido el informe Acceso a la información en materia reproductiva desde una perspectiva de derechos humanos. ${ }^{23}$ En este documento, reconoció que los profesionales de la salud tienen derecho a que se respete su libertad de conciencia. ${ }^{24}$ No obstante, sostuvo:

\section{Ibíd., párr. 338.}

21 Entre otros, pueden verse los siguientes estudios: Paúl, Álvaro, "La Corte Interamericana in vitro: comentarios sobre su proceso de toma de decisiones a propósito del caso Artavia”, Revista Derecho Público Iberoamericano, 2013, 2, pp. 303-345; Henríquez Herrera, Ian, "Comentario al fallo de la Corte Interamericana de Derechos Humanos en el caso Artavia Murillo y otros", Revista Internacional de Derechos Humanos, 2013, III, (3), pp. 55-77; Ramos Kuri, Manuel, "Errores de la Corte Interamericana de Derechos Humanos en el juicio de Costa Rica sobre fertilización in vitro", Bioética, enero-abril 2014, pp. 22-26; Chía, Eduardo \& Conteras, Pablo, "Análisis de la sentencia Artavia Murillo y otros ("fecundación in vitro') vs. Costa Rica de la Corte Interamericana de Derechos Humanos", Estudios Constitucionales, 2014, 12, (1), pp. 567-585.

22 En el párrafo 148 de la sentencia, la Corte IDH afirma: "Los Estados son responsables de regular y fiscalizar la prestación de los servicios de salud para lograr una efectiva protección de los derechos a la vida y a la integridad personal. La salud constituye un estado de completo bienestar físico, mental y social, y no solamente la ausencia de afecciones o enfermedades. En relación con el derecho a la integridad personal, cabe resaltar que para el Comité de Derechos Económicos, Sociales y Culturales, la salud genésica significa que 'la mujer y el hombre están en libertad para decidir si desean reproducirse y en qué momento, y tienen el derecho de estar informados y tener acceso a métodos de planificación familiar seguros, eficaces, asequibles y aceptables de su elección, asi como el derecho de acceso a los pertinentes servicios de atención de la salud" (cursivas fuera del texto original).

$23 \mathrm{CIDH}$, informe Acceso a la información en materia reproductiva desde una perspectiva de derechos bumanos, 22 de noviembre de 2010.

24 Ibíd., párr. 93. 
95. La objeción de conciencia es un tema muy relevante cuando se aborda el acceso a información en materia de salud reproductiva. Muchos profesionales de la salud tienen sus propias convicciones respecto de la utilización de métodos de planificación familiar, de la anticoncepción oral de emergencia, de la esterilización, y del aborto legal, y prefieren no proveer los servicios. [...] el derecho a la objeción de conciencia del profesional de la salud es una libertad. Sin embargo dicha libertad podría colisionar con la libertad de los pacientes. En consecuencia, el equilibrio entre los derechos de los profesionales de la salud y los derechos de los pacientes se mantiene a través de la referencia. Es decir, un profesional de la salud puede negarse a atender a un paciente, pero lo debe transferir sin objeción a otro profesional de la salud que puede proveer lo solicitado por el paciente [...].

99. En este sentido, la CIDH considera que los Estados deben garantizar que las mujeres no se vean impedidas de acceder a información y a servicios de salud reproductiva, y que frente a situaciones de objetores de conciencia en el ámbito de la salud, deben establecer procedimientos de referencia, así como de las sanciones respectivas frente al incumplimiento de su obligación.

En el texto de este informe, se observan dos cuestiones sobre las que se volverá al final del estudio: i) la CIDH hace un reconocimiento expreso de la objeción de conciencia como concreción de una libertad individual; sin embargo, ii) ante el posible conflicto entre esa libertad y los derechos de terceros (pacientes), la tradicional línea de defensa de las libertades individuales en el SIDH no queda tan clara. En este estudio, se propone que, justamente frente a dilemas semejantes, la objeción de conciencia es una salida coherente y eficaz para la defensa de las distintas libertades individuales y su coexistencia armónica en escenarios pluralistas.

\section{Conclusiones}

En suma, el desarrollo del concepto de objeción de conciencia en el SIDH es aún muy incipiente e inexplorado en temas distintos al servicio militar obligatorio. A pesar de ello, resulta interesante que la $\mathrm{CIDH}$ ya lo haya reconocido como un derecho que se deriva de la CADH, y no solo donde aparece expresamente (artículo 6.3.b), sino también, de manera general, en relación con los derechos a la honra y la dignidad (artículo 11) y el derecho a la libertad de conciencia y de religión (artículo 12). No obstante, es un 
derecho que aparece formalmente condicionado a su reconocimiento por parte de los Estados, para lo cual existe un amplio margen de apreciación. Lo anterior significa, en última instancia, que este sería un derecho que se extiende a la Convención, solo a partir de su reconocimiento por los propios Estados, en una clara aplicación del artículo 29.b de la Convención Americana, según el cual "ninguna disposición de la presente Convención puede ser interpretada en el sentido de: [...] b) limitar el goce y ejercicio de cualquier derecho o libertad que pueda estar reconocido de acuerdo con las leyes de cualquiera de los Estados partes [...]”.

Del análisis planteado también se desprende la necesidad de que la Corte IDH pueda llegar a reconocer la autonomía del derecho a la objeción de conciencia, como respuesta a la necesidad creciente de conciliar los conflictos graves que en su fuero interno un individuo pueda afrontar, a causa de obligaciones legales que constriñen sus genuinas convicciones morales, éticas, filosóficas o religiosas, particularmente en el campo de la biomedicina, sabiendo que en una sociedad cada vez más multicultural en la cual los desarrollos tecnológicos son vertiginosos aumenta el número de 'dilemas éticos'. En ese escenario, el necesario balance entre los derechos de los pacientes y el derecho a la libertad de conciencia y religión de quienes prestan los servicios de salud pone de presente la importancia del reconocimiento y regulación de la objeción de conciencia.

\section{La objeción de conciencia en el Sistema Europeo de Derechos Humanos}

\subsection{La objeción de conciencia en el Convenio Europeo para la Protección de los Derechos Humanos y las Libertades Fundamentales}

Al igual que en la Convención Americana sobre Derechos Humanos, el Convenio Europeo para la Protección de los Derechos Humanos y las Libertades Fundamentales (CEDH) hace referencia expresa a la objeción de conciencia únicamente en relación con el derecho a no ser sometido a trabajos forzados. Así, el artículo 4.3.b del Convenio exime de la prohibición del trabajo forzoso u obligatorio "todo servicio de carácter militar o, en los casos de los objetores de conciencia, en los países donde se les reconoce, cualquier otro servicio sustitutivo del servicio militar obligatorio" (cursivas fuera del texto original).

Si bien es cierto que los primeros desarrollos y, quizá, los más consolidados están circunscritos al ámbito de la objeción de conciencia 
al servicio militar, también es verdad que un continente que se enfrenta inexorablemente al desafío de garantizar los derechos de tan diversos grupos que se entremezclan en una sociedad multicultural, ${ }^{25}$ está abocado a que su máximo tribunal, en materia de derechos humanos, afronte nuevos dilemas que ponen de presente, directa o indirectamente, la importancia de la objeción de conciencia, aunque no siempre pueda decirse que haya obrado de modo consistente con esa necesidad.

\subsection{Casos relacionados con el servicio militar obligatorio}

La doctrina y jurisprudencia del SEDH ha pasado por tres etapas importantes frente al desarrollo del derecho a la objeción de conciencia en el servicio militar obligatorio. En una primera etapa (1966-2000), la extinta Comisión Europea fue muy deferente al margen de apreciación de los Estados para decidir si reconocer o no la objeción de conciencia al servicio militar obligatorio, margen que incluía la posibilidad de establecer sanciones penales a los renuentes. En una segunda etapa (2000-2011), el TEDH mantuvo el respeto al margen de apreciación de los Estados, pero impuso límites a la proporcionalidad de las sanciones de los renuentes. En una tercera etapa (2011 en adelante), el TEDH cambió la doctrina de la antigua Comisión e impuso mayores restricciones al margen de apreciación de los Estados en esta materia. En efecto, la nueva jurisprudencia sostiene que la oposición al servicio militar motivada por un conflicto grave e insuperable entre la obligación de servir en el ejército y los deberes de conciencia de un individuo sobre la base de sus creencias arraigadas — sean o no religiosas - puede dar lugar a una violación autónoma del derecho a la libertad de conciencia y religión protegida por el artículo $9^{\circ}$ del Convenio.

\subsubsection{Primera etapa: máxima deferencia al margen de apreciación de los Estados}

En el caso Grandrath vs. Alemania ${ }^{26}$ (1966), la extinta Comisión Europea conoció de la situación de un ministro testigo de Jehová que se presentó

\footnotetext{
25 Esta realidad puede explicar por qué en la Carta de los Derechos Fundamentales de la Unión Europea (2000) se reconoce expresamente el derecho a la objeción de conciencia, artículo 10.2.

26 Comisión EDH, Grandrath vs. Alemania, Aplicación No 2299 de 1964, decisión del 12 de diciembre de 1966.
} 
como 'objetor total' tanto al servicio militar como al servicio civil sustitutivo en Alemania. Fue condenado penalmente por negarse a prestar el servicio civil sustitutivo y alegó violación de su libertad religiosa, del derecho a no ser sometido a trabajos forzados y del principio de no discriminación, en razón a que profesantes católicos y protestantes sí habían estado exentos de este servicio.

La Comisión Europea examinó el caso en virtud del artículo $9^{\circ}$ (libertad de pensamiento, de conciencia y de religión) y en virtud del artículo 14 (prohibición de discriminación), en relación con el artículo $4^{\circ}$ (prohibición del trabajo forzoso u obligatorio) del CEDH. Al respecto, concluyó que Alemania no era responsable de las violaciones, pues cada Estado contratante puede decidir si concede el derecho a la objeción de conciencia para el servicio militar. Adicionalmente, si se le había concedido la objeción de conciencia al servicio militar, el Estado podría exigir el servicio civil sustitutivo. La Comisión también concluyó que los artículos de la ley alemana no eran discriminatorios y, en consecuencia, el peticionario no podía considerarse como víctima de tratos discriminatorios.

Posteriormente, la Comisión conoció de dos casos muy similares: el caso G. Z. vs. Austria ${ }^{27}$ (1973) y el caso X. vs. Alemania ${ }^{28}$ (1977). El primero estaba relacionado con una denuncia en razón de una condena proferida por los tribunales austriacos por haberse negado la presunta víctima a prestar el servicio militar obligatorio en razón a sus creencias religiosas como católico. El denunciante alegó la violación al derecho de libertad de conciencia y religión (artículo $9^{\circ} \mathrm{CEDH}$ ) y la falta de reparación efectiva. En el segundo, se estudió la situación de un testigo de Jehová — reconocido como objetor de conciencia por las autoridades competentes-, quien se negó a cumplir con una llamada a filas para el servicio civil sustitutivo. Por ello, fue condenado a cuatro meses de prisión.

Ambos casos fueron declarados inadmisibles por la Comisión, por encontrarlos manifiestamente infundados. La Comisión afirmó que, a la luz del artículo 4.3.b, los Estados tienen la opción de reconocer o no a los objetores de conciencia y, de ser reconocidos, exigir algún servicio sustituto. Por otra parte, consideró que de una lectura conjunta del derecho a

\footnotetext{
27 Comisión EDH, G. Z. vs. Austria, Aplicación No 5591/92, decisión del 2 de abril de 1973.

28 Comisión EDH, X. vs. Alemania, Aplicación $\mathrm{N}^{\circ} 7705 / 76$, decisión del 7 de mayo de 1977.
} 
libertad de pensamiento, de conciencia y de religión (artículo $9^{\circ} \mathrm{CEDH}$ y del 4.3.b no se podía inferir que existiera una obligación para los Estados de reconocer a los objetores de conciencia y, en consecuencia, de hacer arreglos especiales respecto de la prestación del servicio militar obligatorio. La Comisión también dedujo que los Estados tienen la libertad de sancionar a aquellos que se nieguen injustificadamente a prestar el servicio militar. En el segundo caso, teniendo en cuenta la duración de la condena del solicitante, la Comisión además no encontró argumento convincente en apoyo de sus alegaciones de violación del artículo $3^{\circ}$ (prohibición de tratos inhumanos o degradantes).

Siguiendo esta misma línea de casos, en 1994 la Comisión Europea decidió declarar inadmisible el caso de Peters vs. Holanda. ${ }^{29}$ En esta causa, el demandante, un estudiante de filosofía, fue reconocido como objetor de conciencia, pero se vio obligado a realizar un servicio civil sustitutivo. Dado que los estudiantes de teología tenían, en principio, derecho a ser eximidos de los dos tipos de servicio, el peticionario alegó que se estaba violando el principio de no discriminación, al no extender el mismo beneficio a los estudiantes de filosofía. Si bien la Comisión reconoció que la cuestión planteada por el solicitante estaba comprendida en el ámbito de la libertad de pensamiento, de conciencia y de religión (artículo $9^{\circ} \mathrm{CEDH}$ ), no encontró un indicio de violación al principio de no discriminación (artículo $14 \mathrm{CEDH}$ ), pues consideró que las situaciones no eran asimilables.

\subsubsection{Segunda etapa: deferencia al margen nacional de apreciación y sus límites}

En el año 2000, el TEDH conoció del caso Thlimmenos vs. Grecia, ${ }^{30}$ relativo a la situación de un testigo de Jehová que fue condenado a cuatro años de prisión por insubordinación y dejado en libertad condicional dos años después, por haberse negado a alistarse en el ejército en un momento en el que Grecia no ofrecía servicio alternativo para los objetores de conciencia al servicio militar. Unos años más tarde, en estricta aplicación de la ley nacional, se le negó el nombramiento como auditor de cuentas sobre la base de que contaba en su historial con una condena penal, incluso sabiendo

29 Comisión EDH, Peters vs. Holanda, Aplicación N²2793/93, decisión del 30 de noviembre de 1994.

30 CEDH, Thilmmenos vs. Grecia, Aplicación No 34369/97, decisión del 4 de junio de 2000. 
que había obtenido excelentes resultados en el concurso público para el cargo en cuestión. El TEDH encontró una violación a la prohibición de discriminación (artículo 14 CEDH) en relación con el derecho a la libertad de pensamiento, de conciencia y de religión (artículo $9^{\circ} \mathrm{CEDH}$ ), al considerar que la exclusión del solicitante de la profesión de contador público era desproporcionada en relación con el objetivo de garantizar el adecuado castigo de las personas que se niegan a servir a su país, especialmente considerando que ya había cumplido una pena de prisión.

Este caso resulta interesante, pues, si bien el TEDH no definió que debía garantizarse en todos los Estados el derecho a objetar conciencia frente al servicio militar obligatorio y, de hecho, confirmó la doctrina de que está dentro del margen de apreciación de los Estados la posibilidad de establecer sanciones para quienes no presten el servicio militar, el TEDH sí determinó un criterio nuevo como límite al accionar del Estado: el principio de igualdad. En su argumentación sobre la base de un test de proporcionalidad, los jueces de Estrasburgo advirtieron que aquel principio puede resultar trasgredido no solo cuando se trata de forma desigual a los iguales, sino, como en el presente caso, cuando la ley trata de manera igual situaciones manifiestamente desiguales. ${ }^{31}$

Seis años después, con el caso Ülke vs. Turquía ${ }^{32}$ (2006), el TEDH puso de presente un nuevo límite al margen de apreciación del Estado para regular la objeción de conciencia: la prohibición de infligir tratos inhumanos y degradantes. El actor era un ciudadano turco que se negó a prestar el servicio militar sobre la base de sus creencias pacifistas. Fue condenado nueve veces a prisión, entre otras razones, por incitar a los reclutas a evadir el servicio militar y por su negativa a vestir el uniforme del oficio. Fue encarcelado en ocho ocasiones, cumplió dos años en prisión y, más tarde, se escondió de las autoridades.

El TEDH declaró una violación a la prohibición de tratos inhumanos o degradantes (artículo $3^{\circ} \mathrm{CEDH}$ ). Debido a la naturaleza de la legislación interna, el solicitante corría el riesgo de una serie interminable de procesamientos y condenas penales, por lo cual, según el TEDH, la posibilidad de que el solicitante fuera sujeto a procesamiento durante el resto de su vida, resultaba desproporcionado en relación con el objetivo de asegurar

31 Para un análisis más detenido de este caso, puede verse el estudio de Navarro-Vals y Martínez-Torrón, Conflictos entre conciencia y ley..., op. cit., pp. 100-102.

32 CEDH, Ülke vs. Turquía, Aplicación No 39437/98, decisión del 24 de enero de 2006. 
que prestara el servicio militar. En consecuencia, el trato al que había sido sometido podía ser considerado como degradante, y superaba el umbral de dificultad del trato a que están sometidas las personas pagando una condena penal. Al igual que en el caso Thlimmenos, a pesar de que la Corte no cuestionó la posibilidad de sancionar a las personas que se nieguen a prestar el servicio militar, sí cuestionó la proporcionalidad de la sanción en relación con este delito, esta vez en relación con el derecho a no sufrir tratos degradantes.

\subsubsection{Tercera etapa: margen de apreciación restringido y surgimiento de un derecho autónomo a la objeción de conciencia}

El caso Bayatyan vs. Armenia ${ }^{33}$ (2011) ha sido considerado como un hito en relación con el derecho a la objeción de conciencia. El demandante, un testigo de Jehová, se negó a prestar el servicio militar por razones de conciencia, aunque estaba dispuesto a prestar el servicio civil sustitutivo. Las autoridades le informaron que la posibilidad de realizar servicio sustitutivo había sido derogada en la legislación. Fue declarado culpable de evasión del servicio militar y condenado a prisión. El demandante alegó una violación al artículo $9^{\circ}$ del Convenio y pidió a la Corte que analizara su caso a la luz del principio de interpretación evolutiva de los tratados, esto es, atendiendo a las condiciones actuales, normas y estándares regionales vigentes. Una primera decisión del tribunal negaba las pretensiones del demandante; sin embargo, la Gran Cámara —en el año 2011— acoge el argumento según el cual el Convenio Europeo es un "instrumento vivo" y, por lo tanto, los desarrollos regionales en favor de la tutela a la objeción de conciencia cobraron suficiente peso como para hacer un cambio jurisprudencial de mayor envergadura.

La Gran Cámara del TEDH sostuvo que, si bien el artículo $9^{\circ} \mathrm{CEDH}$ no se refiere de manera explícita al derecho a la objeción de conciencia, este es un derecho autónomo que se desprende de la libertad de conciencia, por lo que debía garantizarse - como cualquier libertad del Conveniode la injerencia arbitraria del Estado. Consecuentemente, una limitación a la libertad de conciencia y religión debía atender estrictamente a los límites definidos en el test de proporcionalidad, esto es, que se trate de

33 Bayatyan vs. Armenia, supra nota 13. Ver también CEDH, Bayatyan vs. Armenia, admisibilidad, Sección Tercera, Aplicación N²3459/03, decisión del 27 de octubre de 2009. 
una medida proporcionada que responda a un fin legítimo y necesario en una sociedad democrática.

En este orden de ideas, para el TEDH, la interpretación del CEDH como "instrumento vivo" permite entender que el artículo $9^{\circ}$ (y no el $4^{\circ}$ ) protege el derecho a la objeción de conciencia, garantizando la libertad personal cuando un individuo se enfrenta a un conflicto serio e ineludible entre la obligación de servir en un ejército y el dictamen contrario proveniente de sus creencias profundas y genuinas. En todo caso, el TEDH advirtió que esta regla no se aplicaba de manera general, sino que siempre debe evaluarse a la luz de las circunstancias particulares de cada caso; ${ }^{34} \sin$ embargo, como se verá adelante, esta doctrina ha sido reiterada en los casos análogos posteriores. En esta nueva jurisprudencia, la Corte manifiesta expresamente separarse del criterio de la extinta Comisión Europea y, en particular, de la interpretación restrictiva que se derivaba del artículo $9^{\circ}$ CEDH, al interpretarlo a la luz del artículo $4^{\circ}$ del Convenio.

Posteriormente, en los casos Erçep vs. Turquía ${ }^{35}$ (2011), Savda vs. Turquia $^{36}$ (2012), Tarhan vs. Turquia ${ }^{37}$ (2012), Feti Demitras vs. Turquía ${ }^{38}$ (2012) y Buldu vs. Turquía ${ }^{39}$ (2014), el TEDH reiteró esta posición. De un análisis conjunto de estos casos, se deducen tres consideraciones importantes. En primer lugar, el tribunal estableció que las sucesivas condenas impuestas a la víctima (testigo de Jehová) por negarse a prestar el servicio militar podían asimilarse a una 'muerte civil' y, por lo tanto, resultaban desproporcionadas e incompatibles con el derecho a un juicio justo (artículo $6^{\circ}$ $\mathrm{CEDH}$. En segundo lugar, el TEDH expresó que Turquía debía regular en su legislación la posibilidad de prestar un servicio civil alternativo al servicio militar. En tercer lugar, se dejó expreso que la objeción de conciencia alegada por las víctimas respondía a un conflicto suficientemente serio entre su obligación de prestar el servicio militar y sus creencias religiosas. Por lo tanto, el Estado también fue hallado responsable de violar el derecho a la

34 CEDH, Bayatyan vs. Armenia, 2011, supra nota 13, párr. 110.

35 CEDH, Erçep vs. Turquía, Aplicación No 43965/04, decisión del 22 de noviembre de 2011.

36 CEDH, Savda vs. Turquía, Aplicación No 42730/05, decisión del 12 de junio de 2012.

37 CEDH, Tarban vs. Turquía, Aplicación No 9078/06, decisión del 17 de julio de 2012.

38 CEDH, Feti Demitras vs. Turquía, Aplicación No 5260/07, decisión del 17 de enero de 2012.

39 CEDH, Buldu vs. Turquía, Aplicación Nº 14017/08, decisión del 3 de septiembre de 2014. 
libertad de conciencia y de religión (artículo $9^{\circ} \mathrm{CEDH}$ ). En algunos de los casos, el TEDH también encontró que las víctimas habían sido maltratadas durante su detención y, por lo tanto, declaró adicionalmente la violación a la prohibición de tratos crueles, inhumanos y degradantes (artículo $3^{\circ} \mathrm{CEDH}$ ).

\subsection{Otros casos: productos farmacéuticos y derecho de propiedad}

Un caso interesante es el de Pichon y Sajous vs. Francia ${ }^{40}$ (2001), relativo a la presunta violación del derecho a la libertad de cultos garantizado por el artículo $9^{\circ}$ del Convenio Europeo. Las presuntas víctimas eran propietarios de una farmacia y se negaron a vender anticonceptivos, con base en sus convicciones religiosas, por lo cual fueron condenados por el Estado. El TEDH señaló que, si bien el artículo $9^{\circ} \mathrm{CEDH}$ protege asuntos de conciencia individual y los actos que están estrechamente vinculados, tales como actos de culto o de devoción que forman parte de la práctica de una religión o una creencia en una forma generalmente aceptada, en la salvaguarda de este dominio personal, el artículo $9^{\circ}$ no siempre garantiza el derecho a comportarse en público de una manera gobernada por esa creencia.

Así, afirmó que la palabra 'práctica' que se utiliza en el artículo 9.1 no denota cada acto o forma de comportamiento motivado o inspirado por una religión o una creencia. El TEDH observó que la venta de anticonceptivos era legal y se produjo por prescripción médica. Por lo tanto, las demandantes no podían dar prioridad a sus creencias religiosas e imponerlas a los demás para justificar su negativa a vender este tipo de productos. El tribunal reiteró que pueden manifestar esas creencias de muchas maneras, no relacionadas con la esfera profesional. Concluyó, entonces, que la condena de los demandantes por la negativa a vender anticonceptivos no interfirió con el ejercicio de los derechos garantizados por el artículo $9^{\circ}$ de la Convención y que la solicitud era manifiestamente infundada.

En el caso Herrmann vs. Alemania ${ }^{41}$ (2012), el accionante era un propietario que se vio obligado por la ley alemana a soportar la caza de animales en su predio. El accionante objetó la caza con base en sus creencias

40 CEDH, Pichon y Sajous vs. Francia, Aplicación No 49853/99, decisión del 2 de octubre de 2001.

41 CEDH, Herrmann vs. Alemania, Aplicación No 9300/07, Gran Sala, decisión del 25 de junio de 2012. 
pacifistas. La Corte manifestó que las acciones realizadas por el Estado implicaban una interferencia con el ejercicio de la propiedad privada al obligar a los propietarios a soportar la presencia de hombres armados y perros de caza en sus terrenos. La Corte reafirmó las decisiones planteadas en los casos Chassagnou y Schneider, ${ }^{42}$ as everando que imponer la cacería a los terratenientes que se oponen a esta sobre la base de creencias éticas implica una carga desproporcionada, incompatible con el artículo $1^{\circ}$ del Protocolo $1 .{ }^{43}$

\subsection{E1 uso de símbolos religiosos y la objeción de conciencia}

En relación con el uso personal de simbología religiosa, el TEDH ha tenido que deliberar sobre su uso e impacto en diversos ámbitos: en el espacio público, en el entorno educativo y en el ámbito laboral. Vale la pena mencionar someramente cuatro casos significativos: Dablab vs. Suiza, ${ }^{44}$ Leyla Sabin vs. Turquia, ${ }^{45}$ Dogru vs. Francia ${ }^{46}$ y Kervanci vs. Francia. ${ }^{47}$ Un análisis conjunto de las cuatro causas permite inferir que, en esta materia, el TEDH ha preferido mantener una línea de respaldo al margen nacional de apreciación de los Estados, autorizando la limitación al uso de símbolos religiosos, en particular, el uso del velo islámico. El debate de fondo en estos casos no se reduce exclusivamente sobre la libertad personal, sino más bien sobre la presencia de la religión en el ámbito público y el laicismo ideológico, que, en busca de una especie de estado 'neutral', pretende reducir las manifestaciones religiosas al ámbito meramente privado, en algunas ocasiones bajo el argumento de preservar la democracia y evitar un presunto avance de posiciones religiosas radicales que generen inestabilidad en los Estados. Evidentemente en Europa, el debate se acentúa y, aunque

42 CEDH, Schneider vs. Luxemburgo, Aplicación No 2113/04, decisión del 10 de julio de 2007. CEDH, Chassagnou vs. Francia, aplicaciones No 25088/94, 28331/95 y 28443/95, decisión del 29 de abril de 1999.

43 Esta disposición se refiere a la protección del derecho a la propiedad.

44 CEDH, Dablab vs. Suiza, Aplicación No 42393/98, decisión del 15 de febrero de 2001.

45 CEDH, Leyla Sabin vs. Turquía, Aplicación No 44774/98, decisión del 29 de junio de 2004.

46 CEDH, Dogru vs. Francia, Aplicación No 27058/05, decisión del 4 de diciembre de 2008.

47 CEDH, Kervanci vs. Francia, Aplicación No 31645/04, decisión del 4 de diciembre de 2008 . 
no exclusivamente, refleja una cierta inquietud sobre la identidad cultural del Viejo Continente y la presencia creciente de inmigración musulmana. ${ }^{48}$

Una decisión que contrasta parcialmente con la tendencia expuesta es Eweida vs. Reino Unido ${ }^{49}$ (2013), por lo que merece una referencia especial, aunque no puede sostenerse que en realidad haya un cambio jurisprudencial, puesto que, por un lado, el dilema de fondo que se plantea no está determinado por el aparente conflicto entre libertad de religión y Estado laico, en sus versiones turca y francesa, y, por otro, como se explicará enseguida, solo una de las peticionarias resultó favorecida con la decisión del tribunal. El caso engloba la situación de cuatro distintas peticionarias que alegan discriminación en el ámbito laboral a causa de la manifestación de sus creencias religiosas. Eweida era trabajadora de una aerolínea y se le prohibió portar una cruz en su cuello con base en el código de conducta de la empresa, amenazándola con suspenderle el pago o cambiarla a un puesto en que no tuviera que atender público. Chaplin era una enfermera que usaba una cadena con una cruz en el cuello, y se le pidió que la retirara por el riesgo que podría acarrear para sus pacientes de la tercera edad, si alguno pudiera halarla. Tuvo que ser trasladada a un empleo administrativo, que luego fue suprimido. Ladele era una notaria encargada de registrar matrimonios, nacimientos y defunciones. A raíz de un cambio normativo que obligaba a registrar uniones de parejas homosexuales, la peticionaria objetó dicho requerimiento debido a sus creencias cristianas. Fue disciplinada y amenazada con despido. McFarlane era una consejera de pareja que fue sancionada por negarse a aconsejar a parejas del mismo sexo en temas sexuales en razón de sus creencias cristianas.

El Tribunal de Estrasburgo declaró que se violó la libertad de conciencia y religión frente a la primera peticionaria, pero no frente a las tres restantes. En su sentencia reiteró que la libertad religiosa abarca la libertad de manifestar las creencias de manera privada, pero también engloba su práctica en comunidad con otros y en público. Dichas manifestaciones de creencias religiosas pueden tomar forma de adoración, enseñanza,

48 Por la complejidad de esta cuestión y los propósitos de este estudio, no se ahondará en esta perspectiva. Más bien, se referencia un análisis detallado y extenso del debate político, cultural y jurídico en Europa, así como los derroteros de la jurisprudencia del TEDH sobre el particular: Navarro-Vals y Martínez-Torrón, Confictos entre conciencia y ley ..., op. cit., pp. 317-417.

49 CEDH, Eweida vs. Reino Unido, aplicaciones No 48420/10, 59842/10, 51671/10 y 36516/10, decisión del 15 de junio de 2013. 
práctica y observación. Como la manifestación de las creencias religiosas de la persona puede tener impacto en otros, sus restricciones deben estar prescritas en la ley, ser necesarias en una sociedad democrática y perseguir un interés legítimo. ${ }^{50}$ A su vez, para contar como 'manifestación' en el sentido del artículo $9^{\circ} \mathrm{CADH}$, el acto en cuestión debe estar íntimamente relacionado con la religión o creencia. Pero la existencia de un nexo lo suficientemente cercano y directo entre la conducta y la creencia detrás debe ser determinada conforme a los hechos del caso y no es necesario probar que se trata de un mandato preciso de la religión en cuestión.

Las opiniones disidentes de los jueces Vučinić y De Gaetano en relación con la tercera peticionaria resultan del mayor interés para ilustrar uno de los propósitos de este trabajo, cual es rescatar la importancia de la objeción de conciencia como un derecho que facilita la interacción armónica entre distintas libertades individuales que pueden entrar en tensión en ciertos casos difíciles. Para los dos jueces, el TEDH se equivocó al negar la violación de los derechos a la libertad de conciencia y religión, así como el derecho a la no discriminación de la notaria, quien, en virtud de sus convicciones cristinas, se negaba a registrar como matrimonio las uniones de parejas homosexuales. En su argumentación, la cuestión central no es tanto la libertad de religión como la libertad de conciencia protegida en el artículo $9^{\circ} \mathrm{CEDH}$ y, de acuerdo con la cual: "Nadie debe ser obligado a actuar contra su propia conciencia o ser penalizado por negarse a actuar contra su conciencia". ${ }^{51}$ En este voto, se hace un especial énfasis en la importancia que tiene para un individuo el juicio moral o de la conciencia,

50 Los jueces Bratza y David Thór Björgvinsson se apartaron de la decisión mayoritaria en relación con la primera peticionaria, justamente porque consideraron que no resultaba aplicable en el caso de Eweida el argumento central del TEDH según el cual una restricción al artículo $9^{\circ} \mathrm{CEDH}$ para que sea legítima requiere superar el test de proporcionalidad, esto es, que "las restricciones deben estar prescritas en la ley, ser necesarias en una sociedad democrática y perseguir un interés legítimo". En el sentir de los jueces disidentes, este criterio aplicaría si fuera el Estado quien hubiera estado implicado directamente en la alegada discriminación, y no, como en el caso, una compañía aérea que no actúa en nombre del Estado. En este sentido, los jueces argumentaron que lo que tendría que haber valorado el tribunal es el cumplimiento de las obligaciones positivas del Estado para garantizar el derecho consagrado en el artículo $9^{\circ} \mathrm{CEDH}$ y no si la restricción era necesaria en una sociedad democrática o si el Estado había cumplido con las obligaciones negativas derivadas de aquella provisión convencional.

51 Opinión separada de los jueces Vučinić y De Gaetano, caso Eweida vs. Reino Unido, 15 de enero, 2013, párr. 2 (traducción libre de las autoras). 
protegido por la objeción de conciencia y diferente del contenido propio de la libertad religiosa. En este sentido, afirman: "Este juicio racional sobre lo que es bueno y lo que es malo, a pesar de que puede ser alimentado por las creencias religiosas, no es necesariamente así, y la gente sin creencias o afiliaciones religiosas particulares hace tales juicios constantemente en su vida diaria". 52

La discordancia de los jueces con el voto de la mayoría está sobre todo basada en los efectos jurídicos que se derivan del contenido y alcance del derecho de objeción de conciencia, y la violación al principio de igualdad y no discriminación, que, a juicio de estos dos jueces, había sufrido la peticionaria. Según ellos, el TEDH se equivocó en su decisión, puesto que en el caso de la Sra. Ladele sus creencias no tuvieron un impacto en el contenido de su trabajo, sino solo en el alcance de este. Tampoco se probó que ella hubiera intentado imponer sus creencias a los demás, de manera abierta o subrepticiamente, por lo que el hecho de haber perdido su trabajo resultaba totalmente desproporcionado. De ahí que en su voto enfatizan en la importancia de que en los sistemas jurídicos se reconozca la objeción de conciencia y el Estado respete su ámbito de aplicación. ${ }^{53}$ Desafortunadamente solo se trata de un voto separado y no de la opinión de la mayoría; sin embargo, considerando que se trata de una opinión muy reciente, fruto de una interpretación evolutiva del Convenio Europeo, en la que se hace manifiesta la necesidad de garantizar la coexistencia armónica de los derechos y libertades fundamentales en sociedades pluralistas, caben esperanzas de que esta visión se abra camino en el Tribunal de Estrasburgo y, dicho sea de paso, en el SIDH.

52 Ibíd., párr. 3 (traducción libre de las autoras).

53 En este sentido, los jueces expresaron: "Una vez que se ha establecido un caso real y grave de objeción de conciencia, el Estado está obligado a respetar la libertad individual de conciencia tanto positiva (mediante la adopción de medidas razonables y apropiadas para proteger los derechos de los objetores de conciencia) como negativamente (absteniéndose de las acciones que castigan el objetor o discriminan en su contra). La libertad de conciencia en el pasado con demasiada frecuencia ha culminado en actos de heroísmo, ya sea a manos de la Inquisición española o de un pelotón de fusilamiento nazi [...] 'con el fin de evitar que la obediencia a la conciencia de uno aún termine en un acto de heró́smo, es que ahora la ley garantiza la libertad de conciencia". Ibíd. (traducción libre de las autoras). 


\subsection{La objeción de conciencia frente a tratamientos médicos}

La Corte Europea también ha tenido la oportunidad de conocer algunos casos relacionados con la discusión de si existe o no un derecho al aborto. Aunque la Corte ha reconocido que no existe tal derecho protegido por el Convenio, sí ha adoptado decisiones que le exigen a los Estados cumplir con su legislación si esta permite la interrupción del embarazo bajo ciertas circunstancias, ${ }^{54}$ y también ha planteado que el Estado debe garantizar que dicha interrupción, cuando está autorizada por ley, pueda ser efectivamente practicada en las instituciones de salud..$^{55}$ En ese sentido, la Corte reconoce y admite la legislación nacional referida a la objeción de conciencia de personal médico, sin embargo, se cuestiona al Estado que aun contando con dicha regulación no se asegure de que la práctica se ajuste a lo previsto legalmente, de tal suerte que resulten ineficaces los derechos de los pacientes. ${ }^{56}$ Aquella exigencia de garantizar la práctica de la interrupción del embarazo cuando esté previsto en la ley nacional conlleva, entonces, un debate aún vigente sobre el alcance y titularidad del derecho a la objeción de conciencia, no solo individual, sino también por parte de las instituciones de salud, aspecto muy problemático sobre todo cuando son de carácter privado y tienen un ideario contrario a dichas prácticas.

Justamente en atención a esa preocupación, la Asamblea Parlamentaria del Consejo de Europa en su Resolución 1763 de 2010 afirmó:

1. Ninguna persona, hospital o institución será coaccionada, considerada civilmente responsable o discriminada debido a su rechazo a realizar, autorizar, participar o asistir en la práctica de un aborto, la realización de un aborto involuntario o de emergencia, eutanasia o cualquier otro acto que cause la muerte de un feto humano o un embrión, por cualquier razón.

2. La Asamblea Parlamentaria enfatiza la necesidad de afirmar el derecho a la objeción de conciencia junto a la responsabilidad del Estado

\footnotetext{
54 CEDH, A, B, C vs. Irlanda, Gran Sala, Aplicación No 25579/05, 16 de diciembre de 2010.

55 CEDH, R. R. vs. Polonia, Sección Cuarta, 26 de mayo de 2011, Aplicación No 27617/04 y P. y S. vs. Polonia, Aplicación No 57375/08, decisión del 5 de noviembre de 2012.

56 CEDH, P.y S. vs. Polonia, Aplicación $\mathrm{N}^{\circ}$ 57375/08, decisión del 5 de noviembre de 2012, párr. 107.
} 
de asegurar que los pacientes tienen un acceso adecuado a la atención sanitaria prevista por la ley [...].

3. En la gran mayoría de los Estados miembros del Consejo de Europa, la práctica de la objeción de conciencia está regulada de modo adecuado $[\ldots]$.

4. A la luz de las obligaciones de los Estados miembros de asegurar el acceso a los servicios y prestaciones sanitarias admitidas por la ley y de proteger el derecho a la protección de la salud, así como su obligación de asegurar el respeto al derecho a la libertad ideológica, de conciencia y religión de los profesionales sanitarios, la Asamblea invita a los Estados miembros del Consejo de Europa a desarrollar marcos legales claros y completos que definan y regulen la objeción de conciencia en relación con los servicios médicos y de salud, los cuales:

4.1. Garanticen el derecho a la objeción de conciencia en relación con la participación en el procedimiento en cuestión.

4.2. Aseguren que los pacientes son informados de cualquier objeción, en un plazo adecuado, así como que son derivados a otro profesional sanitario.

4.3. Aseguren que los pacientes reciben tratamiento adecuado, en particular en casos de emergencia.

Esta resolución resulta de suma importancia, ya que es quizás el único instrumento internacional que reconoce expresamente el derecho a la objeción de conciencia, no solo del personal sanitario, sino incluso de las instituciones, tratándose de la prestación de servicios médicos. De hecho, esta posición se opone a la línea adoptada por otros instrumentos de carácter no vinculante que, como se verá en el siguiente apartado relativo a los órganos de la ONU, instan a los Estados a garantizar que las instituciones como tal no objeten conciencia frente a tratamientos tales como las prácticas de abortos.

\section{Conclusiones}

Al igual que en el SIDH, la jurisprudencia más extensa y reiterada sobre objeción de conciencia ha estado muy circunscrita al ámbito del servicio militar obligatorio. Sin embargo, a diferencia de lo que ha ocurrido en el SIDH, el número de casos y el surgimiento de un consenso europeo en torno al reconocimiento de la objeción de conciencia, particularmente en relación con el servicio militar obligatorio, han generado un cambio jurisprudencial 
importante que empieza a separarse de la regla tradicional que concede especial deferencia al margen de apreciación de los Estados. Sin duda, este cambio jurisprudencial está directamente relacionado con la tendencia del tribunal regional a limitar el margen de apreciación cuando encuentra un consenso europeo sobre temas que en principio deberían ser decididos por los Estados.

Como pudo observarse, a diferencia del SIDH, el contexto europeo está requiriendo un mayor número de pronunciamientos en diversidad de asuntos que, en última instancia, ofrezcan respuesta a dilemas de alto contenido político y cultural: el lugar de la religión en el ámbito público de Estados que propugnan el laicismo; las tensiones entre diversas identidades culturales; las amenazas a la democracia generadas por la presencia creciente de alegados partidos fundamentalistas; el balance entre la libertad personal y los derechos de terceros, de manera muy especial en el ámbito de los servicios médicos. Indudablemente, la complejidad de las situaciones enmarcadas en estos desafíos sociales profundos explica los desacuerdos en el interior del TEDH a la hora de zanjar las causas judiciales, las muchas críticas que en los temas más sensibles reciben las decisiones del tribunal y una cierta expectativa sobre las soluciones que prometan los mejores derroteros para salvaguardar los derechos humanos de todas las personas en sociedades completamente multiculturales.

\section{La objeción de conciencia en el Sistema Universal de Derechos Humanos}

\subsection{Objeción de conciencia al servicio militar obligatorio}

La Comisión de Derechos Humanos de las Naciones Unidas profirió una serie de resoluciones para promover el derecho a la objeción de conciencia al servicio militar obligatorio. En efecto, en las resoluciones 1989/59, 1995/83, 1993/84, 1998/77, 2000/34, 2002/45 y 2004/35, entre otras cuestiones, la Comisión reconoce el derecho de toda persona a objetar conciencia al servicio militar, como ejercicio legítimo del derecho a la libertad de pensamiento, conciencia y religión reconocido en el artículo 18 de la Declaración Universal de Derechos Humanos (DUDH) y en el artículo 18 del Pacto Internacional de Derechos Civiles y Políticos (PIDCP). Así mismo, hace un llamado a los Estados para que promulguen leyes y adopten medidas destinadas a eximir del servicio militar sobre la base de una auténtica objeción de conciencia al servicio armado; recomienda 
adoptar posibilidades de servicio civil alternativo y resalta que no debe existir discriminación entre creencias, para efectos de objetar conciencia.

En 1993, el Comité de Derechos Humanos del PIDCP (CDH) profirió la Observación General 22 sobre el derecho a la libertad de pensamiento, conciencia y religión (artículo 18 del Pacto). ${ }^{57}$ En dicha observación, el Comité sostuvo:

11. [...] En el Pacto no se menciona explícitamente el derecho a la objeción de conciencia pero el Comité cree que ese derecho puede derivarse del artículo 18, en la medida en que la obligación de utilizar la fuerza mortífera puede entrar en grave conflicto con la libertad de conciencia y el derecho a manifestar y expresar creencias religiosas u otras creencias. Cuando este derecho se reconozca en la ley o en la práctica, no habrá diferenciación entre los objetores de conciencia sobre la base del carácter de sus creencias particulares; del mismo modo, no habrá discriminación contra los objetores de conciencia porque no hayan realizado el servicio militar ${ }^{58}$ (cursivas fuera del texto original).

Lo que resulta interesante de esta observación es que, a pesar de que el CDH reconoce que el derecho a la objeción de conciencia se puede derivar del artículo 18, aunque no se mencione explícitamente en el PIDCP, lo cierto es que lo restringe exclusivamente al tema del servicio militar obligatorio y no lo analiza de una manera más amplia. Es de hecho la única mención a la objeción de conciencia a lo largo de toda la observación general.

En el informe preliminar sobre la eliminación de toda forma de intolerancia religiosa preparado por el Relator Especial de la Comisión de Derechos Humanos en 1997, el Relator reitera que el derecho a la objeción de conciencia es un derecho "íntimamente ligado con la libertad de religión". ${ }^{99}$ A renglón seguido, recuerda las resoluciones de la Comisión de Derechos Humanos de las Naciones Unidas en relación con la objeción

\footnotetext{
57 Observación General 22, Comentarios generales adoptados por el Comité de los Derechos Humanos, artículo 18, Libertad de pensamiento, de conciencia y de religión, $48^{\circ}$ período de sesiones, U.N. Doc. HRI/GEN/1/Rev.7 at 179 (1993).

58 Ibíd., párr. 11.

59 Relator Especial sobre libertad religiosa de la Comisión de Derechos Humanos, Informe preliminar sobre la eliminación de toda forma de intolerancia religiosa, 16 de octubre de 1997, párr. 77.
} 
de conciencia al servicio militar obligatorio. ${ }^{60}$ Aunque en este informe parece reconocerse de una manera más general el derecho a la objeción de conciencia, al igual que en anteriores oportunidades, se relaciona con el servicio militar.

Así mismo, en el informe provisional de la Relatora Especial sobre la libertad de religión o de creencias de agosto de 2007, se recordó que el derecho a la objeción de conciencia al servicio militar obligatorio se deriva del artículo 18 del PIDCP y se instó a los Estados a que siempre que, en las circunstancias de cada caso concreto se cumplieran los demás requisitos de la definición de refugiado conforme al Estatuto de los Refugiados (1951), "consideren la posibilidad de conceder asilo a los objetores de conciencia obligados a abandonar su país de origen por temor a ser perseguidos debido a su negativa a cumplir el servicio militar y no existir ninguna disposición adecuada sobre la objeción de conciencia al servicio militar". ${ }^{61}$ Reconoció también que algunas organizaciones internacionales y regionales han señalado que las personas que están cumpliendo el servicio militar pueden transformarse con el tiempo en objetores de conciencia. ${ }^{62}$

En 2007, el CDH profirió su Observación General 32 sobre el derecho a un juicio imparcial y la igualdad ante los tribunales y cortes de justicia. En dicha observación, el Comité afirmó que "los castigos reiterados a objetores de conciencia por no haber obedecido repetidos mandamientos de incorporación a filas para cumplir el servicio militar pueden equivaler a otras tantas sanciones por un único delito si la consiguiente negativa a acatarlos se apoya en la misma e invariable determinación basada en razones de conciencia". ${ }^{63}$

Por último, en el informe analítico sobre la objeción de conciencia al servicio militar del Alto Comisionado de las Naciones Unidas para los Derechos Humanos de 2013, se reiteraron las resoluciones de la antigua Comisión de Derechos Humanos, las decisiones y observaciones de los comités convencionales de las Naciones Unidas sobre objetores de conciencia al servicio militar, y se recordó, entre otros aspectos, que no pueden

\footnotetext{
60 Ibíd., párr. 78.

61 Relatora Especial sobre la libertad de religión o de creencias, Informe provisional de la Relatora Especial sobre la libertad de religión o de creencias, 20 de agosto de 2007, A/62/280.

62 Ibíd.

63 Observación General 32, Comentarios generales adoptados por el Comité de los Derechos Humanos, articulo 14. El derecho a un juicio imparcialy a la igualdad ante los tribunales y cortes de justicia, $90^{\circ}$ período de sesiones, CCPR/C/GC/32, 23 de agosto de 2007, párr. 55.
} 
existir circunstancias en las que pueda anularse el derecho a la objeción de conciencia al servicio militar, ni siquiera bajo estados de excepción, teniendo en cuenta la jurisprudencia del Comité según la cual la objeción de conciencia "es inherente al derecho de pensamiento, de conciencia y de religión", y que el encarcelamiento reiterado por objetar conciencia es contrario a los postulados del Pacto.

El Comité del PIDCP también constató el derecho a la objeción de conciencia en denuncias de particulares. En J. P. vs. Canadáa ${ }^{64}$ (1991) la presunta víctima alegó objeción de conciencia al pago de impuestos destinados a actividades militares, a causa de sus convicciones religiosas. El Comité afirmó que, si bien el Pacto reconocía la objeción de conciencia al servicio militar, la objeción al pago de los impuestos destinados a actividades militares se escapaba del ámbito de protección del derecho a la libertad de conciencia y de religión.

En el caso Brinkof vs. Holanda ${ }^{65}$ (1993), la víctima fue condenada penalmente por negarse a prestar el servicio militar en razón de sus convicciones pacifistas. El peticionario alegaba que existía una discriminación en razón a que solo se consideraban objetores de conciencia a los testigos de Jehová y no a personas que manifestaran otras creencias. El Comité consideró que la exención de un solo grupo de objetores de conciencia y la inaplicabilidad de la exención para todos los demás no puede considerarse razonable. En este contexto, el CDH remitió a su Observación General 22 y subrayó que, cuando un derecho a la objeción de conciencia al servicio militar es reconocido por un Estado parte, no se hará distinción entre los objetores de conciencia sobre la base de la naturaleza de sus creencias particulares. Sin embargo, en el caso concreto, el Comité consideró que el autor no demostró que sus convicciones como un pacifista fueran incompatibles con el sistema de servicio social sustitutivo en los Países Bajos o que el trato privilegiado concedido a los testigos de Jehová hubiera afectado negativamente sus derechos como objetor de conciencia del servicio militar.

En el caso Foin vs. Francia ${ }^{66}(1999)$, la presunta víctima alegaba que la exigencia de un servicio civil por el doble de tiempo que el servicio militar

64 J. P. vs. Canadá, Comunicación No 446/1991, U.N. Doc. CCPR/C/43/D/446/1991, pars. 36 (1991).

65 Brinkhof vs. The Netherlands, Comunicación No 402/1990, U.N. Doc. CCPR/ C/48/D/402/1990 (1993).

66 Comité de Derechos Humanos, Foin vs. Francia, Comunicación No 666/1995, U.N. Doc. CCPR/C/67/D/666/1995, 9 de noviembre de 1999. 
constituía una discriminación, cuando no se ha prestado el servicio militar por razones de objeción de conciencia. El CDH reiteró su posición de que el artículo 26 no prohíbe todas las diferencias de trato, aunque cualquier diferenciación debe estar basada en criterios razonables y objetivos. En este contexto, el CDH reconoció que la ley y la práctica pueden establecer diferencias entre el servicio militar y otro servicio alternativo, y que tales diferencias pueden, en casos particulares, justificar un período de servicio más largo, por criterios tales como la naturaleza del servicio en cuestión o la necesidad de una formación especial para prestarlo. Sin embargo, en el caso en cuestión, el Comité consideró que las razones aducidas por el Estado parte no se referían a tales criterios o solo mencionaban criterios en términos generales sin especificar la situación particular del autor, sino que se basaban en el argumento de que la duplicación de la duración del servicio es la única manera de probar la sinceridad de las convicciones del individuo. En opinión del Comité, este argumento no satisface el requisito de que la diferencia de trato se basaba en criterios razonables y objetivos. Así, el CDH consideró que existió una violación del artículo 26, ya que el autor fue objeto de discriminación sobre la base de su convicción de conciencia.

En el caso Westerman vs. Holanda ${ }^{67}$ (1999), la presunta víctima alegaba violación a sus derechos por haber sido sancionado al negarse a cumplir actividades propias del servicio militar, el cual tuvo que prestar dado que Holanda no lo reconoció como objetor válido de conciencia. El Comité observó que las autoridades del Estado evaluaron los hechos y argumentos presentados por el autor en su reclamación de la exención como objetor de conciencia a la luz de las disposiciones legales y que estas disposiciones eran compatibles con las disposiciones del artículo 18 del PIDCP. Por consiguiente, determinó que el autor no demostró frente a las autoridades que él tenía una objeción de conciencia insalvable al servicio militar, por lo que no podía deducirse responsabilidad alguna para el Estado.

Por último, en los casos Yoony Choi vs. la República de Corea (2007), Jung y otros vs. la República de Corea, y Jeong y otros vs. la República de Corea (2011), el Comité reiteró que el derecho a la objeción de conciencia se deriva del artículo 18, aunque no se mencione explícitamente, y que dicho derecho existe a pesar de la formulación del artículo $8^{\circ}$ del PIDCP, que establece que “no se considerarán como ‘trabajo forzoso u obligatorio’ [...] el servicio

67 Comité de Derechos Humanos, Westerman vs. Holanda, Comunicación No 682/1996, U.N. Doc. CCPR/C/67/D/682/1996, 13 de diciembre de 1999. 
de carácter militar y, en los países donde se admite la exención por razones de conciencia, el servicio nacional que deben prestar, conforme a la ley, quienes se opongan al servicio militar por razones de conciencia". En el caso Yoon, el Comité estableció que el artículo $8^{\circ}$ PIDCP ni reconoce ni excluye el derecho a la objeción de conciencia y, por ello, la denuncia se examinó únicamente a tenor del artículo 18 del Pacto.

Esta decisión es significativa porque revierte la doctrina anterior, paralelamente a lo que sucedió en el Sistema Europeo. De hecho, el Comité en el caso LTK vs. Finlandia ${ }^{68}$ (1985) había dictaminado que del Pacto no se derivaba el derecho a la objeción de conciencia y que, en sentido estricto, el artículo $8^{\circ}$ excluía la obligación de los Estados de garantizar la objeción de conciencia al servicio militar. Este cambio de concepción se presentó entonces en ambos sistemas de protección de derechos humanos.

\subsection{Práctica de aborto, eutanasia y tratamientos médicos}

En contraste con las pocas directrices regionales consolidadas en esta materia, diversos órganos del Sistema de Protección de Derechos Humanos de las Naciones Unidas han emitido sus conceptos, privilegiando siempre los derechos de terceros, en presunto conflicto sobre el derecho a la objeción de conciencia. Esto no deja de ser llamativo por contradictorio, como se concluirá en la parte final de este artículo.

El Comité para la Eliminación de la Discriminación contra la Mujer ha manifestado su preocupación por "el creciente recurso a la objeción de conciencia de los profesionales de la salud en la ausencia de un marco regulatorio adecuado" ${ }^{69}$ y "la insuficiente regulación del ejercicio de la objeción de conciencia de los profesionales de la salud con respecto a la salud sexual y reproductiva". ${ }^{70}$ En consecuencia, ha instado a los Estados partes a garantizar que "las mujeres que buscan un aborto legal tengan acceso a ese procedimiento, y que su acceso no esté limitado por el uso de la cláusula de objeción de conciencia"; $; 1$ a "establecer un marco regulatorio

\footnotetext{
68 Comité de Derechos Humanos, LTK vs. Finlandia, Comunicación No 185/1984, U.N. Doc. CCPR/C/OP/2 at 61 (1990), 9 de julio de 1985.

69 Observaciones finales de Hungría, ONU CEDAW/C/HUN/CO/7-8 (2013), párr. 30.

70 Comité para la Eliminación de la Discriminación contra la Mujer, Observaciones finales de Eslovaquia, [A/63/38] (2008), párr. 42.

71 Comité para la Eliminación de la Discriminación contra la Mujer, Observaciones finales de Polonia, CEDAW/C/POL/CO/6 (2007), párr. 392.
} 
adecuado y el mecanismo de seguimiento de la práctica de la objeción de conciencia de los profesionales de la salud y asegurarse que la objeción de conciencia se acompaña de información a las mujeres acerca de las alternativas existentes y que sigue siendo una decisión personal y no de una práctica institucionalizada"; 72 y para asegurar que "el acceso de las mujeres a la salud y la salud reproductiva no se limite". ${ }^{73}$ En relación con la objeción de conciencia institucional, el Cedaw ha afirmado que "[t]ambién le preocupa la información en relación con la negativa, porparte de algunos hospitales, para proveer abortos, basándose en la objeción de conciencia de los médicos. El Comité considera que se trata de una infracción de los derechos reproductivos de las mujeres". ${ }^{74}$

Así mismo, en su Recomendación General 24 sobre la mujer y la salud (artículo 12 CEDAW), haciendo referencia a los servicios de salud reproductiva, el Comité manifestó que, "si los encargados de prestar servicios de salud se niegan a prestar esa clase de servicios por razones de conciencia, deberán adoptarse medidas para que remitan a la mujer a otras entidades que prestan esos servicios". ${ }^{75} \mathrm{Y}$, si bien apela a la referencia como solución, resulta clara la reticencia del Comité para admitir la importancia de la objeción de conciencia en un campo en el que naturalmente aparece una diversidad de dilemas éticos serios para el personal sanitario.

\section{Conclusiones}

Del análisis expuesto resulta evidente que en el Sistema Universal, la tendencia ha sido hacia un creciente reconocimiento de la objeción de conciencia como un derecho autónomo en el ámbito del servicio militar obligatorio. Sin embargo, al mismo tiempo se puede observar cómo la objeción de conciencia resulta, más que un derecho, un obstáculo para el ejercicio de los derechos sexuales y reproductivos. Estas dos posiciones contradictorias frente a la figura de objeción de conciencia resultan problemáticas para la construcción de un verdadero derecho a la objeción de conciencia con

\footnotetext{
72 Observaciones finales de Hungría, op. cit.

73 Comité para la Eliminación de la Discriminación contra la Mujer, Observaciones finales de Eslovaquia, op. cit.

74 Comité para la Eliminación de la Discriminación contra la Mujer, Observaciones finales de Croacia, Doc. de la ONU A/53/38/Rev.1 (1998).

75 CEDAW, Recomendacion General 24: artículo 12 CEDAW, La mujer y la salud, $20^{\circ}$ período de sesiones $(02 / 02 / 1999)$.
} 
la autonomía propia que requiere y, sobre todo, de cara a definir marcos jurídicos consistentes tanto en el ámbito nacional como internacional.

\section{A modo de colofón: perspectivas para el Sistema Interamericano}

Del recuento crítico y sistematización de los principales casos que desarrollan la doctrina de la objeción de conciencia en los sistemas comparados de derechos humanos, se pueden sacar conclusiones y lecciones. Las conclusiones se han ido anticipando en cada acápite en relación con el ámbito de cada sistema, por lo que aquí corresponde plantear conclusiones derivadas de una mirada comparativa y de conjunto. La intención es concluir para aprender, es decir, para entender algunas de las lecciones que la experiencia universal y europea pueden ofrecer al Sistema Interamericano con el ánimo de enriquecer el debate académico sobre un tema de trascendental importancia en nuestros días; de ahí que el esquema que se propone sea numérico y puntual.

4.1. Los principales tratados internacionales de derechos humanos reconocen expresamente la objeción de conciencia solo respecto del servicio militar obligatorio. Dentro de este espectro, en los últimos años se ha forjado una tendencia en el Sistema Europeo y en el Sistema Universal que la caracteriza como un derecho autónomo, garantía de una libertad fundamental, al menos en el ámbito del servicio militar. En las más recientes decisiones, los tribunales y órganos competentes en los dos sistemas han declarado explícitamente que la objeción de conciencia no está sujeta al margen de apreciación de los Estados de manera irrestricta, por lo que se han establecido los mismos límites que operan frente a otros derechos. Es en este sentido que, en particular el TEDH, ha acudido al test de proporcionalidad para verificar si es que una medida restrictiva del derecho persigue un fin legítimo y resulta necesaria en una sociedad democrática.

4.2. Por contraste, los casos del SIDH resueltos solo por la CIDH no permiten aún entrever la misma tendencia. Sin embargo, sobre la base de la experiencia, es posible pensar que un caso como Bayatyan puede llegar a tener eco en Latinoamérica. En todo caso, no pueden eludirse las dificultades que para algunos países del continente podrían acarrear la eliminación del servicio militar obligatorio y los altos costos políticos que de allí derivarían. 
4.3. El punto de inflexión que el caso Bayatyan representa en la jurisprudencia europea deja ver una perspectiva para el Sistema Interamericano: el reconocimiento del derecho a la objeción de conciencia en el servicio militar — condicionado por el derecho nacional_ a la luz del artículo 6.3.b no implica que este sea el único sustento del derecho a la objeción de conciencia en la Convención Americana, ni que tal provisión afecte, limite o matice el contenido del artículo 12 CADH en cuanto reconoce el derecho a la libertad de conciencia y religión. Por el contrario, si la jurisprudencia europea llegara a tener impacto en el Sistema Interamericano, como sería deseable en este punto, los órganos del SIDH tendrían que empezar a reconocer la autonomía del derecho a la objeción de conciencia sobre la base del artículo $12 \mathrm{CADH}$.

4.4. Un mayor y más sólido reconocimiento del derecho a la objeción de conciencia en otros campos distintos al servicio militar no solo aparece como necesario, sino también como coherente. Es necesario porque en una sociedad pluralista urgen medidas que faciliten la convivencia pacífica de los muy distintos idearios; en ese sentido, el derecho a la objeción de conciencia es una alternativa a la fuerza y a la violencia, pues justamente armoniza las distintas libertades fundamentales que podrían entrar en tensión en situaciones que se plantean como insuperables en el marco del fuero interno de un individuo o, incluso, la identidad esencial de una institución. En el SIDH pueden ofrecerse al menos dos razones generales que abogan por el reconocimiento de la objeción de conciencia como una condición de coherencia. En primer lugar, el SIDH siempre ha sido reticente a admitir el margen nacional de apreciación (originario del $\mathrm{SEDH}$ ), de manera que, tratándose de proteger una libertad fundamental como la libertad de conciencia expresamente protegida en la CADH, lo más consecuente es que el SIDH no deje al completo arbitrio de los Estados una medida necesaria para proteger tal libertad: la objeción de conciencia. En segundo lugar, un reconocimiento del derecho autónomo a la objeción de conciencia sobre la base del artículo 12 CADH sería coherente con el alto valor que la jurisprudencia de la Corte IDH ha otorgado al pluralismo y la protección de la identidad cultural.

4.5. Paradójicamente, la tendencia a un reconocimiento cada vez más autónomo de la objeción de conciencia en el marco del servicio militar obligatorio contrasta con la tendencia también notoria de considerar a la objeción de conciencia ya no como un derecho, sino como un obstáculo para el ejercicio de los derechos sexuales y reproductivos. Esta conclusión se hace evidente de las opiniones vertidas al respecto por el CEDAW, 
por el Comité del PIDCP e, incluso, por la Comisión Interamericana de Derechos Humanos. Como mencionara José López Guzmán en su libro, resulta irónico el planteamiento de que el derecho proteja a la persona que no quiere empuñar un arma, pero deje indefenso al que no quiere utilizar un bisturí. ${ }^{76}$

Esa visión fraccionada de la objeción de conciencia acarrea un cierto debilitamiento de la institución jurídica que por antonomasia resuelve los más serios y genuinos conflictos entre obligaciones de conciencia y obligaciones de ley, escenarios extremos y no poco frecuentes, considerando, entre otros contextos, el desarrollo vertiginoso de la biomedicina y el multiculturalismo como consecuencia de la globalización. Y, aunque el monopolio de los casos de multiculturalismo se ubicó en Europa, el continente americano no está lejos de la misma realidad. Aquí, por ahora, el tema del islam no será la prioridad, pero de muchos otros modos la diversidad étnica y cultural de los pueblos de América representa un desafío. En el mismo sentido obran los retos que plantea la biomedicina y, sin embargo, la Corte IDH, que hubiera podido avanzar en este frente, desaprovechó la oportunidad que le ofrecía el caso Artavia sobre fecundación in vitro.

4.6. Todo lo anterior muestra una necesidad creciente de ampliar el debate académico acerca del derecho a la objeción de conciencia como un derecho autónomo protegido por los tratados internacionales de derechos humanos, el lugar del margen de apreciación de los Estados en la definición de su contenido y el papel que puede jugar la objeción de conciencia ya no solo para la protección de los individuos, sino de las personas jurídicas. Si bien es cierto que, por los propósitos del presente estudio no se hizo énfasis en la cuestión de la titularidad de este derecho, no es menos cierto que algunos de los dilemas éticos a los que se ha aludido los enfrentan también instituciones con idearios éticos o religiosos esenciales a su identidad, por lo que aparece manifiesta la importancia de seguir avanzando en un diálogo académico sobre el tema. Este artículo tenía como propósito evidenciar el estado del arte en el derecho internacional y subrayar algunas cuestiones problemáticas, todo con el fin de alentar tan necesario debate en una sociedad pluralista.

76 López Guzmán, ¿Qué es la objeción de conciencia?, op. cit., p. 25. 


\section{Referencias bibliográficas}

\section{Casos}

CEDH, A, B, C vs. Irlanda, Gran Sala, Aplicación No 25579/05, 16 de diciembre de 2010.

CEDH, Buldu vs. Turquía, Aplicación No 14017/08, decisión del 3 de septiembre de 2014.

CEDH, Chassagnou vs. Francia, aplicaciones No 25088/94, 28331/95 y 28443/95, decisión del 29 de abril de 1999.

CEDH, Dablab vs. Suiza, Aplicación No 42393/98, decisión del 15 de febrero de 2001.

CEDH, Dogru vs. Francia, Aplicación No 27058/05, decisión del 4 de diciembre de 2008.

CEDH, Erçep vs. Turquia, Aplicación No 43965/04, decisión del 22 de noviembre de 2011.

CEDH, Eweida vs. Reino Unido, Aplicaciones No 48420/10, 59842/10, 51671/10 y 36516/10, decisión del 15 de junio de 2013.

CEDH, Feti Demitras vs. Turquía, Aplicación No 5260/07, decisión del 17 de enero de 2012.

CEDH, Glass vs. Reino Unido, Sección Cuarta, Aplicación No 61827/00, decisión del 9 de marzo de 2000.

CEDH, Herrmann vs. Alemania, Aplicación No 9300/07, Gran Sala, decisión del 25 de junio de 2012.

CEDH, Kervanci vs. Francia, Aplicación No 31645/04, decisión del 4 de diciembre de 2008.

CEDH, Leyla Sabin vs. Turquía, Aplicación No 44774/98, decisión del 29 de junio de 2004.

CEDH, Pichon y Sajous vs. Francia, Aplicación No 49853/99, decisión del 2 de octubre de 2001.

CEDH, R. R. vs. Polonia, Sección Cuarta, 26 de mayo de 2011, Aplicación No 27617/04 y P.y S. vs. Polonia, Aplicación No 57375/08, decisión del 5 de noviembre de 2012.

CEDH, Savda vs. Turquía, Aplicación No 42730/05, decisión del 12 de junio de 2012.

CEDH, Schneider vs. Luxemburgo, Aplicación No 2113/04, decisión del 10 de julio de 2007.

CEDH, Tarhan vs. Turquía, Aplicación No 9078/06, decisión del 17 de julio de 2012. 
CEDH, Thilmmenos vs. Grecia, Aplicación No 34369/97, decisión del 4 de junio de 2000.

CEDH, Ülke vs. Turquía, Aplicación No 39437/98, decisión del 24 de enero de 2006.

CIDH, caso Alfredo Díaz Bustos vs. Bolivia, Informe No 97/05, Petición 14/04, Solución amistosa, 27 de octubre de 2005.

CIDH, caso Luis Gabriel Caldas León vs. Colombia, No $137 / 10$, Informe N ${ }^{\circ}$ 137/10, Caso 11.596, 23 de octubre de 2010.

CIDH, Sabli Vera vs. Chile, Caso 12.219, Informe No 43/05, 10 de marzo de 2005.

Comisión EDH, Peters vs. Holanda, Aplicación No 22793/93, decisión del 30 de noviembre de 1994.

Comisión EDH, G. Z. vs. Austria, Aplicación No 5591/92, decisión del 2 de abril de 1973.

Comisión EDH, Grandrath vs. Alemania, Aplicación No 2299 de 1964, decisión del 12 de diciembre de 1966.

Comisión EDH, X. vs. Alemania, Aplicación No 7705/76, decisión del 7 de mayo de 1977.

Comité de Derechos Humanos, Foin vs. Francia, Comunicación No 666/1995, U.N. Doc. CCPR/C/67/D/666/1995, 9 de noviembre de 1999.

Comité de Derechos Humanos, Dr. J. P. vs. Canada, Comunicación No 446/1991, U.N. Doc. CCPR/C/43/D/446/1991, par. 36 (1991).

Comité de Derechos Humanos, LTK vs. Finlandia, Comunicación N ${ }^{\circ}$ 185/1984, U.N. Doc. CCPR/C/OP/2 at 61 (1990), 9 de julio de 1985.

Comité de Derechos Humanos, Westerman vs. Holanda, Comunicación $\mathrm{N}^{\mathrm{o}}$ 682/1996, U.N. Doc. CCPR/C/67/D/682/1996, 13 de diciembre de 1999.

Corte IDH, caso Artavia Murillo y otros (fecundación in vitro) vs. Costa Rica, excepciones preliminares, fondo, reparaciones y costas, sentencia del 28 de noviembre de 2012, Serie C No 257.

\section{Libros}

Llamazares Fernández, Dionisio \& Llamares Calzadilla, María Cruz, Derecho de la libertad de conciencia, Aranzadi Civitas, Navarra, 2007.

López Guzmán, José, ¿Qué es la objeción de conciencia?, Serie Persona y Cultura, Eunsa, Pamplona, 2011.

Navarro-Vals, Rafael \& Martínez-Torrón, Javier, Conflictos entre conciencia y ley: las objeciones de conciencia, Iustel, Madrid, 2012. 
Sierra Madero, Dora María, La objeción de conciencia en México. Bases para un adecuado marco jurídico, UNAM, México, 2012.

\section{Artículos}

Cañamares Arribas, Santiago, "La evolución de la doctrina del Tribunal Europeo de Derechos Humanos en materia de objeción de conciencia”, Revista de Derecho Público, 2014, 23, (46), pp. 37-58.

Chía, Eduardo \& Conteras, Pablo, "Análisis de la sentencia Artavia Murillo y Otros ("fecundación in vitro') vs. Costa Rica de la Corte Interamericana de Derechos Humanos", Estudios Constitucionales, 2014, 12, (1), pp. 567-585.

Henríquez Herrera, Ian, "Comentario al fallo de la Corte Interamericana de Derechos Humanos en el caso Artavia Murillo y otros", Revista Internacional de Derechos Humanos, 2013, III, (3), pp. 55-77.

Martínez-Torrón, Javier, "El derecho internacional y las objeciones de conciencia”, en Objeción de conciencia, Colección Cuadernos del Instituto de Investigaciones Jurídicas, UNAM, 1998, pp. 111-136.

Paúl, Álvaro, "La Corte Interamericana in vitro:comentarios sobre su proceso de toma de decisiones a propósito del caso Artavia", Revista Derecho Público Iberoamericano,2013, 2, pp. 303-34.

Ramos Kuri, Manuel, "Errores de la Corte Interamericana de Derechos Humanos en el juicio de Costa Rica sobre fertilización in vitro", Bioética, enero-abril 2014, pp. 22-26.

\section{Otros instrumentos}

Comisión de Derechos Humanos, Relator especial sobre libertad religiosa, Informe preliminar sobre la eliminación de toda forma de intolerancia religiosa, 16 de octubre de 1997.

Comisión de Derechos Humanos, Relatora especial sobre la libertad de religión o de creencias, Informe provisional de la Relatora Especial sobre la libertad de religión o de creencias, 20 de agosto de 2007, A/62/280.

Comité para la Eliminación de la Discriminación contra la Mujer, Observaciones finales de Eslovaquia, [A/63/38] (2008).

Comité de Derechos Humanos, Observación General 32, Comentarios generales, artículo 14, El derecho a un juicio imparcial y a la igualdad ante los tribunales y cortes de justicia, $90^{\circ}$ período de sesiones, CCPR/C/GC/32, 23 de agosto de 2007. 
Comité para la Eliminación de la Discriminación contra la Mujer, Observaciones finales de Polonia, CEDAW/C/POL/CO/6 (2007).

Comité para la Eliminación de la Discriminación contra la Mujer, Observaciones finales de Croacia, Doc. de la ONU A/53/38/Rev.1 (1998).

Comité para la Eliminación de la Discriminación contra la Mujer, Recomendación General 24: artículo 12 CeDAw, La mujer y la salud, $20^{\circ}$ período de sesiones (02/02/1999).

Comité para la Eliminación de la Discriminación contra la Mujer, Observaciones finales de Hungría, ONU CEDAW/C/HUN/CO/7-8 (2013). 